\title{
A CASE REPORT ON DIGOXIN INTOXICATION IN A CLINICAL PHARMACIST'S PERSPECTIVE
}

\author{
SARANYA PUNNIYAKOTTI ${ }^{1 *}$, BENAZEER BEGUM N² ${ }^{2}$ ASHOK KUMAR M $^{1}$
}

${ }^{1}$ Department of Pharmacy Practice, School of Pharmaceutical Sciences, Vels Institute of Science, Technology and Advanced Studies, Pallavaram, Chennai, Tamil Nadu, India. ${ }^{2}$ Department of Pharmacy Practice, School of Pharmaceutical Sciences, Vels Institute of Science, Technology and Advanced Studies, Pallavaram, Chennai, Tami Nadu, India. Email: saro08bpharm@gmail.com

Received: 10 October 2018, Revised and Accepted: 11 December 2018

\begin{abstract}
Context: Digoxin is a commonly used inotropic drug that has a narrow therapeutic range and is monitored poorly for its plasma concentration. It is commonly used in the management of cardiovascular disorders for its inotropic effects. Increased risk of chronic digoxin toxicity among the patients receiving digoxin pharmacotherapy is related to its narrow therapeutic range. Apart from its inotropic properties, it can also produce chronotropic and dromotropic effect. Its serum levels vary due to changes in body weight, age, renal function, hepatic impairment, and concomitant drug administrations. Patients receiving digoxin should be monitored periodically for potential drug interactions, adverse effects, toxicity, and other drugrelated problems. Symptoms of digoxin-induced cardiotoxicity are difficult to be identified and may become fatal too. Therapeutic drug monitoring will play a significant role in reducing such drug therapy problems and will ensure safety and efficacy of the given drug.
\end{abstract}

Case Report: We report a case of chronic digoxin toxicity in a 22-year-old male with congestive cardiac failure - Class IV and atrial fibrillation with ventricular bigeminy.

Results: Patient's renal parameters were elevated and among electrolytes, sodium level was decreased and potassium level was increased. A reduction in the volume of the distribution of digoxin, due to impairment of renal function or congestive cardiac failure, might be one of the reasons for digoxin toxicity. Drug therapy problems (DTPs) such as untreated indication, inappropriate drug therapy, potential major drug-drug interactions, and drugs prescribed when contraindicated were observed.

Conclusion: Monitoring digoxin drug therapy can bring down the risk of digoxin intoxication.

Keywords: Digoxin toxicity, Digoxin plasma concentration, Therapeutic drug monitoring, Therapeutic range, Cardiovascular disease, Case report.

(C) 2018 The Authors. Published by Innovare Academic Sciences Pvt Ltd. This is an open access article under the CC BY license (http://creativecommons. org/licenses/by/4. 0/) DOI: http://dx.doi.org/10.22159/ajpcr.2018.v11s4.31736

\section{INTRODUCTION}

Digoxin, a cardiac glycoside, is commonly used in the management of cardiovascular disorders such as congestive cardiac failure and cardiac arrhythmias for its inotropic effects. Increased risk of chronic digoxin toxicity among the patients receiving digoxin pharmacotherapy is related to its narrow therapeutic range $(0.8-$ $2 \mathrm{ng} / \mathrm{ml}$ ) [1]. Apart from its inotropic properties, it can also produce chronotropic and dromotropic effect [2]. Symptoms of digoxininduced cardiotoxicity are difficult to be identified and may become fatal too [3]. In this article, we discuss a case of digoxin intoxication in a clinical pharmacist perspective.

\section{CASE REPORT}

A 22-year-old man, Mr. X, was admitted to the coronary care unit through emergency.

\section{Presenting complaint}

Mr. X had been suffering from abdominal pain, reduced urine output, loss of appetite (symptoms of digoxin toxicity), loss of weight, and constipation for the past 1 week. He was also suffering from excessive cough and Class II-IV dyspnea. After admission, on the $6^{\text {th }}$ day, he developed visual disturbance and delirium.

\section{Mmedical history}

Mr. X's medical history included acyanotic congenital heart disease, congestive cardiac failure-Class IV, hyperacidity, and asthma. He was diagnosed with congenital corrected transposition of the great arteries at 17 years of age.

\section{Medication history}

Mr. X was on the following medications:

- Digoxin $0.25 \mathrm{mg}$ OD

- Furosemide $20 \mathrm{mg}$ BD

- $\quad$ Seroflo inhaler 2 puffs TDS

He was on irregular follow-up in multiple hospitals with anti-heart failure medications.

\section{Physical examination}

On examination, Mr. X was found to have AF with a pulse rate of 72 beats per minute (irregular). His jugular venous pressure (JVP) elevated up to the angle of mandible (An elevated JVP is typically a sign of congestive heart failure) and " $\mathrm{A}$ " wave was absent (the absence of " $\mathrm{A}$ " wave is seen in atrial fibrillation [AF]). He also had pedal edema up to knee and facial puffiness - ++

\section{Systems examination}

Cardiovascular system(CVS): Upon CVS examination, Heart sound S1 was normal whereas S2 was irregular with apical impulse hyperdynamic over right midaxillary region. Parasternal heave was positive, grade IV/ VI presystolic murmur over apical area and grade II/VI high pitched early diastolic murmur over pulmonary area was observed. A positive bilateral air entry and fine crepts was perceived on examining the respiratory system. Upon palpation, per abdomen was soft, fluid was present (++) and huge hepatomegaly was noticed.

Other investigation results

Other investigation results were as follows: 
Table 1: Drugs contraindicated in this patient with its reason $[4,5]$

\begin{tabular}{ll}
\hline Drug & Reason for contraindication (as per BNF) \\
\hline Digoxin & Intermittent complete heart block, atrial fibrillation, heart failure, and renal impairment \\
Dobutamine & Increases the risk of rapid ventricular response in patients with a history of atrial fibrillation. \\
Fentanyl & Renal or hepatic impairment \\
Furosemide & Hyponatremia, anuria, or renal failure. Hepatic or renal impairment \\
Pantoprazole & Hepatic impairment \\
Spironolactone & Hyperkalemia, hyponatremia, anuria, and renal impairment (avoid if renal parameters rapidly deteriorating) \\
Tramadol & Renal or hepatic impairment \\
\hline
\end{tabular}

- Blood pressure $110 / 70 \mathrm{mmHg}$.

- Respiratory rate 18 breaths per minute.

- ECG showed AF with ventricular bigeminy and complete heart block suggestive of digoxin toxicity.

- ECHO showed situs solitus, dextrocardia, severe pulmonary arterial hypertension (PAH), severe left-sided atrioventricular (AV) valve regurgitation, mild right-sided $\mathrm{AV}$ valve regurgitation, dilated left atrial, intra-atrial septum (IAS) bulging toward the right atrium, intact IAS/intraventricular septum, and severe biventricular dysfunction.

- Chest X-ray showed dextrocardia, pruning of pulmonary artery, cardiomegaly and cardiothoracic ratio -0.8 , and Grade II PAH.

- Creatinine $1.7 \mathrm{mg} / \mathrm{dl}$ (normal range 0.6-1.2)

- Urea $140 \mathrm{mg} / \mathrm{dl}(7-20 \mathrm{mg} / \mathrm{dl})$

- Sodium $115 \mathrm{mmol} / \mathrm{L}(136-145 \mathrm{mmol} / \mathrm{L})$

- Potassium $6.12(3.5-5 \mathrm{mmol} / \mathrm{L})$

- Other electrolytes levels were normal, including calcium and magnesium.

- Total bilirubin $6.5 \mathrm{U} / \mathrm{L}(0.3-1 \mathrm{U} / \mathrm{L})$

- Direct bilirubin $1.5 \mathrm{U} / \mathrm{L}(0.1-0.3 \mathrm{U} / \mathrm{L})$

- Indirect bilirubin $4.6 \mathrm{U} / \mathrm{L}(0.2-0.7 \mathrm{U} / \mathrm{L})$

- Digoxin $3.6 \mathrm{ng} / \mathrm{ml}(0.8-2 \mathrm{ng} / \mathrm{ml})$

\section{Diagnosis}

The patient was diagnosed with acyanotic congenital heart disease, congestive cardiac failure (class IV), AF with ventricular bigeminy and digitalis toxicity.

\section{Management}

The patient was symptomatically treated pending his biochemical and clinical investigation results. After the patient developed visual disturbances and delirium (symptoms of digoxin toxicity), digoxin was stopped immediately. Mr. X was managed symptomatically and improved very well initially. Transposition of the right arteries with intact septum was corrected, and then, the case was discussed in a multidisciplinary heart team meeting and was advised orthotropic heart transplantation. Meanwhile, Mr. X's bilirubin levels got elevated and he deteriorated once again developing acute renal failure (ARF). Even though he was treated with inotropes symptomatically, no further significant improvement was observed in his condition, and therefore, the only treatment option left behind was heart transplantation.

\section{DTP involved}

DTPs are usually related to indication, effectiveness, safety, and adherence of drug therapy. DTPs observed in this patient are listed as follows:

Potential drug interactions:

\begin{tabular}{lll}
\hline Category & Number of interactions & Drugs \\
\hline Major & 6 & Calcium+Digoxin \\
& & Digoxin+Dopamine \\
& Digoxin+Spironolactone \\
& Fentanyl+Morphine \\
& Fentanyl+Tramadol \\
& Morphine+Tramadol \\
\hline
\end{tabular}

Seven moderate and two minor potential drug-drug interactions were also observed.

Untreated indication: Huge hepatomegaly.

Wrong Dose: Milrinone $0.01 \mathrm{mcg} / \mathrm{kg} / \mathrm{min}$ was given to Mr. X.

However, the recommended dose of milrinone for CHF patients.

- Loading dose: $50 \mathrm{mcg} / \mathrm{kg}$ over $10 \mathrm{~min}$ and the maintenance dose is titrated based on the hemodynamic and clinical response.

- Maintenance dose: $0.375-0.75 \mathrm{mcg} / \mathrm{kg} / \mathrm{min}$.

\section{Contraindications}

The Table 1 indicates the drugs that are contraindicated and the clinical reason for its forbidden use in this patient.

\section{DISCUSSION}

\section{Causes of digoxin toxicity}

Digoxin is a drug with narrow therapeutic range and its serum levels vary due to changes in body weight, age, renal function, hepatic impairment, and concomitant drug administrations. An impaired volume of the distribution of digoxin, due to reduced renal function (digoxin is excreted mainly by the kidneys) or congestive cardiac failure, might be one of the reasons for digoxin toxicity [6,7]. In Mr. X's case, his renal function was deteriorating and he developed ARF and congestive cardiac failure.

Chadha et al. have reported that digoxin is a drug with narrow therapeutic index and can cause life-threatening arrhythmias when the plasma levels rise $>2 \mathrm{ng} / \mathrm{ml}$. Renal insufficiency interactions with other drugs that affect digoxin metabolism and electrolyte abnormalities (particularly hypokalemia) are the risk factors for digoxin toxicity $[8,9]$. Similarly, Mr.X's renal parameters were elevated and among electrolytes, sodium level was decreased and potassium level was increased to $6.12 \mathrm{mmol} / \mathrm{L}$. Hyperkalemia is a major concern in digoxin toxicity $[10,11]$. Potential drug-drug interactions might have also summed up the risk of hyperkalemia in him. Sani has reported that concomitant drugs prescribed (such as amiodarone, calcium antagonists, quinine, diuretics, and indomethacin) may interfere with the plasma protein binding of digoxin [4]. Mr. X was also receiving diuretics that might have increased the risk of digoxin toxicity.

Bremner et al. have stated that it is significant to monitor plasma electrolyte levels and $\mathrm{pH}$ frequently in patients with digoxin toxicity. Digoxin intoxication may lead to hyperkalemia by generalized cellular loss of potassium with subsequent cardiac arrest. Induction of hyperkalemia has been proposed as a therapeutic measure in digoxin overdosage, as elevated plasma potassium levels antagonize glycoside uptake at the sodium-potassium pump site $[4,12,13]$. In context to that, Mr. X's potassium level was also elevated and hyperkalemia was left untreated monitoring potassium levels frequently.

\section{Clinical features of digoxin toxicity}

In Mr. X's case, cardiac effects include complete heart block and noncardiac effects are abdominal pain, reduced urine output, loss of appetite, visual disturbances, and delirium. This can be supported the statement of Sani, "clinical features of digoxin toxicity can be categorized into cardiac and non-cardiac effects" [6]. 
Mr. X was discharged on request despite being in an unstable condition (inotropic support). He was given furosemide, losartan, and pantoprazole.

\section{CONCLUSION}

Patients receiving digoxin, a drug with narrow therapeutic index should be monitored periodically for potential drug interactions, adverse effects, toxicity, and other drug-related problems. Therapeutic drug monitoring will play a significant role in reducing such DTP and will ensure safety and efficacy of the given drug.

\section{ACKNOWLEDGMENT}

The authors thank the management of Vels Institute of Science, Technology and Advanced Studies for their support. The authors extend their sincere thanks to the physician, patient, and staff nurses of Frontier Lifeline Hospital, Mugappair, Chennai - 600101.

\section{REFERENCES}

1. Juneja D, Singh O, Bhasin A, Gupta M, Saxena S, Chaturvedi A, et al. Severe suicidal digoxin toxicity managed with resin hemoperfusion: A case report. Indian J Crit Care Med 2012;16:231-3.

2. Szponar J, Tchórz M, Drelich G, Gnyp L, Lewandowska-Stanek H.
Severe digoxin poisoning a case study. Przegl Lek 2011;68:515-7.

3. Acharya TA, Mehta DS, Vekariya RS. Digoxin toxicity: Crucial to diagnose. Int J Basic Clin Pharm 2012;1:39-40.

4. British National Formulary. British National Formulary. $61^{\text {st }}$ ed. London: British National Formulary, BMJ Group; 2011.

5. Vittalrao AM, Thanusubramanian H, Kumari KM, Shaik AB. Pharmacotherapy of heart failure. Asian J Pharm Clin Res 2018;11: 78-87.

6. Sani M. A case of digoxin toxicity in uncontrolled atrial fibrillation. $\mathrm{Br}$ J Clin Pharm 2009;1:15.

7. Mordasini MR, Krähenbühl S, Schlienger RG. Appropriateness of digoxin level monitoring. Swiss Med Wkly 2002;132:506-12.

8. Chadha S, Lodha A, Shetty V, Sadiq A, Hollander G, Shani J. A case of 2:1 atrio -ventricular block in digoxin toxicity. J Clin Exp Cardiol 2011; 2:154.

9. Viera, AJ, Wouk N. Potassium disorders: Hypokalemia and hyperkalemia. Am Fam Physician 2015;92:487-95

10. Davey M. Calcium for hyperkalaemia in digoxin toxicity. Emerg Med J 2002;19:183.

11. Rahmawati F, Hidayati N, Rochmah W, Sulaiman SA. Potentiality of drug-drug interactions in hospitalized geriatric patients in private hospital, Yogyakarta, Indonesia. Asian J Pharm Clin Res 2010;3:191-4.

12. Bremner WF, Third JL, Lawrie TD. Massive digoxin ingestion. Report of a case and review of currently available therapies. Br Heart J 1977; 39:688-92.

13. Pincus M. Management of digoxin toxicity. Aust Prescr 2016;39:18-20. 